\title{
UNDERSTANDING AND MONITORING ENVIRONMENTAL PERFORMANCE OF INFRASTRUCTURE DESIGN PROJECTS
}

\author{
Mansour Salamé, Joseph; \\ Leroy, Yann; \\ Saidani, Michael; \\ Nicolai, Isabelle \\ Université Paris-Saclay, CentraleSupélec, Laboratoire Genie Industriel
}

\begin{abstract}
The formalization of environmental issues has gained prominence since the definition of sustainable development by the Brundtland's report. Environmental performance has then been introduced to qualify the "green" contribution of an organization to its surrounding environment. However, its multi-dimensional aspects can be problematic when designing projects and making decisions, especially in the infrastructure sector where industrial activities are the most polluting ones. The aim of the study is to fill the environmental gap and confusion for decision-makers on the understanding of environmental performance, as well as to communicate on it, to define and share a clear vision and targets. A literature review is conducted and confronted with an industrial example in the railway sector to analyze the existing misunderstandings in industries while approaching environmental issues. By proposing and setting a clear framework of environmental performance, this research contributes to the conceptualization of environmental performance. More precisely, it characterizes an environmentally performant design project, in order to consider environmental performance as a driver and catalyzer of value creation.
\end{abstract}

Keywords: Sustainability, Ecodesign, Project management, Environmental performance, Railway industry

Contact:

Mansour Salamé, Joseph

CentraleSupelec - University Paris Saclay

Laboratoire Genie Industriel

France

joseph.mansoursalame@centralesupelec.fr 


\section{INTRODUCTION}

Sustainable development, defined in Brundtland report (WCED, 1987), as "development that meets the needs of the present without compromising the ability of future generations to meet their own needs", has resulted in the formalization of environmental issues. This formalization has led to various agreements as Agenda 21 (Rio Earth Summit), 2030 Agenda (definition of the sustainable development goals), and Paris Agreement on Climate Change.

Environmental awareness and institutional pressure (command and control approaches) have boosted green policy adoption (Dou and Cao, 2020). Public opinion entered the stakes, associating legitimacy to companies' environmental activities, and more globally, to general sustainable preoccupations.

In this context, the concept of environmental performance emerged in organizations as a significant interest in the environmental field. However, the multi-faceted aspects of this concept can be misleading and generate misapprehensions, false decisions, or conflicts between stakeholders (Siegel and Summermatter, 2008). Despite various individual initiatives, coordinated actions can struggle with defining an environmental performance for industrial activities or projects.

Although several norms have been defined (ISO 14001 on environmental management systems, ISO 14040 on life cycle analysis of product systems and ISO 14031 on environmental evaluation), a lack of shared understanding of the environmental performance persists in industry and between its different actors. The literature develops tools to identify key performance indicators (KPI) or to manage environmental processes. However, to the best of our knowledge, this gap of miscomprehension remains unclear.

For example, the norm ISO 14001 defines environmental performance as the measurable results of environmental management systems. This definition may be challenging to translate into actionable environmental indicators and decisions-making processes. Definitions are essential to monitor processes and achieve objectives (Moullin, 2007).

In this context, the railway infrastructure sector is no exception. Hence, it is pertinent to contribute to the conceptualization of environmental performance for infrastructure design projects. The purpose of this paper is firstly to identify the dimensions of environmental performance from a literature review. This review is then confronted with an industrial example that studies the understanding of the environmental performance in infrastructure design projects, considered the most polluting ones (Cabello Eras et al., 2013). Recommendations follow for a better comprehension of the environmental performance in the design and steering of infrastructure projects.

\section{RESEARCH APPROACH}

Toward understanding environmental performance, our research question is: How to characterize and improve the environmental performance of an infrastructure design project?

The first part of this paper exerts a systematic literature review (Garza-Reyes, 2015) on the concept of performance, and then environmental performance, as well as its dimensions using databases such as Web of Science and Google Scholar.

The keyword search applied to title is: performance, environmental performance, sustainable projects, construction projects, infrastructure projects, railway, sustainability, and eco-design.

The selection excludes all articles that are not written in English or French; the title should not be oriented to a specific environmental technology. Finally, the choice is based on the abstract reading. Apart from France, the review did not focus on a particular country.

The second part of this paper studies the example of SNCF Réseau, a railway infrastructure manager. A survey is addressed to the actors of its industrial projects, asking them about their vision of environmental performance. These actors are classified by their contribution to the design or execution phases of projects. A double comparison is then drafted on:

- the different participants' understandings of environmental performance according to the project phase

- $\quad$ literature and industrial comprehensions

By cross-referencing bibliography and industrial results, the aim of this research is to study the different levels of apprehension of environmental performance in order to identify existing shortcomings in drawing relevant criteria for a more sustainable infrastructure design project. 


\section{ENVIRONMENTAL PERFORMANCE: A LITERATURE REVIEW}

\subsection{The concept of performance}

Performance is ambiguous, multidimensional, and complex (Siegel and Summermatter, 2008). This term is used in all fields with different meanings: from sports (performance of the athletes) to the economic and industrial domains (performance of an organization). Furthermore, in the same field, it is not always easy to characterize it. This is mainly due to its different understandings that differ depending on the persons, their position, their culture, and the problems they face. That is why we speak about subjectivity of the concept. Ghalem et al. (2016) explain that no standard definition can be attributed to performance because of its changeable nature depending on the context. Defining a performance is as difficult as characterizing its dimensions and criteria. For Lebas (1995), the term itself is even more frustrating to understand than its measures seem.

\subsubsection{A global vision}

Bourguignon (1997) has clarified some aspects of performance using a three-dimensional definition reused by many other research pieces: success, result, and action.

Performance is a conceptual notion related to the context and the addressed stakeholders. It represents what an organization considers as a success, a favourable result. Performance is assimilated to the fulfilment of objectives characterized by their internal coherence (economic, societal, environmental) and their relevance (according to the organization's strategy and its stakeholders). Success is deduced from measurements and results. The difference between success and result is a value judgment. For Pesqueux (2005), performance is a quantified result from a ranking perspective. For Lebas (1995), having accomplished the objectives once does not mean they will be achieved again. Their fulfilment is then related to effectiveness (degree of target achievement) and efficiency (degree of consumed resources to reach the level of targets' achievement) (Ghalem et al., 2016).

Therefore, performance is also the action that follows organizational objectives and leads to results. Performance is the action and its results. It is associated with a notion of process. Therefore, to have a performant action, the question would be "How to conduct a performant process?" after answering "What is a performant process?"

Figure 1 resumes these main ideas. Performance is action, results, and success. The action drives the processes evaluated by measurements. Data analysis of these measurements forms the results. Success is defined as value creation according to objectives to fulfil. Value creation is issued from the results and the value judgment of stakeholders, internal or external to the organization. A critical factor influences the definition: the time related to processes, measurements, and objectives.

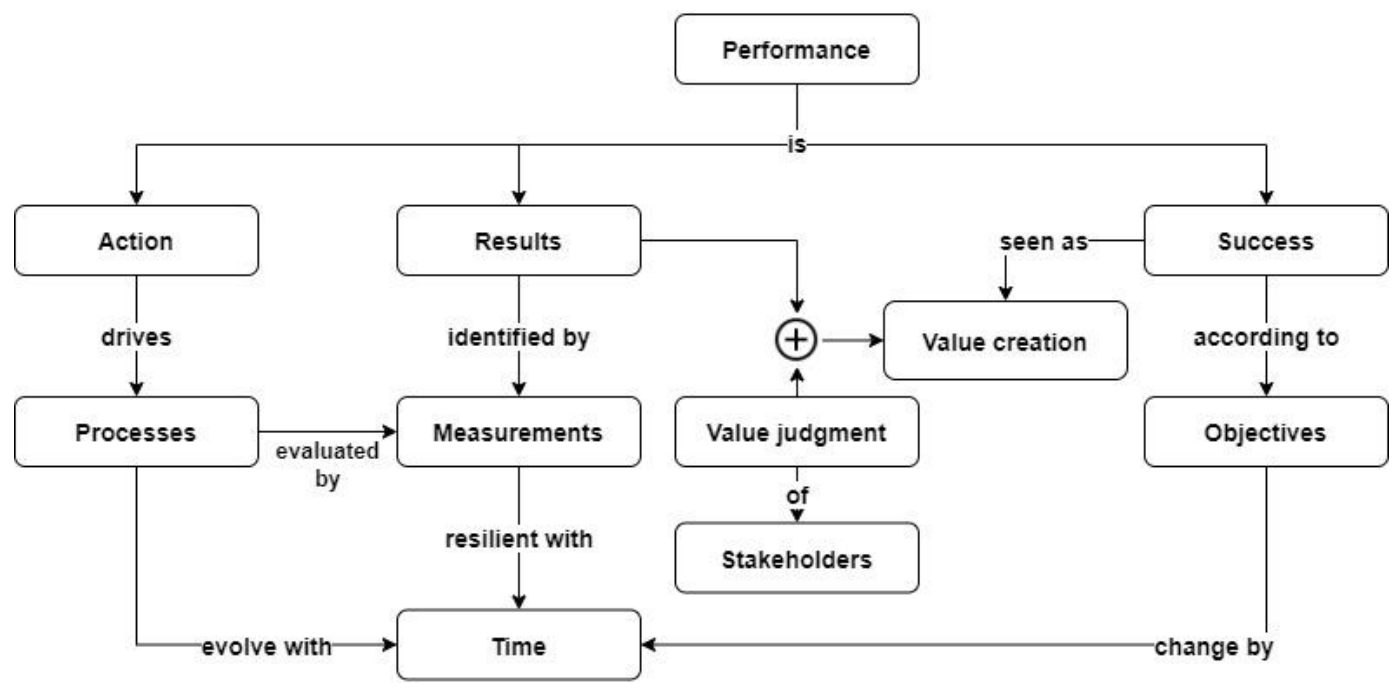

Figure 1. Definition of performance according to the literature review (Source: Authors)

\subsubsection{From performance to global performance}

Performance is success understood as value creation. This value has long been considered economic and financial regarding the survival of the company in its competitive environment. However, considering sustainable policy, performance acquires a broader and universal dimension. It is then 
called global performance. This notion joins two vague concepts: "performance" and "globality" (Pesqueux, 2005). Global performance brings together company's social and environmental performances. It combines all strategic fields, including environmental objectives, by adopting management systems, in a perspective of value creation for all: company, stakeholders, society and environment, in the short, medium and long terms. It is thus essential to define and characterize firstly what is called environmental performance.

\subsection{Environmental performance: A multidimensional definition}

\subsubsection{An "oriented" multi-faceted concept}

An intuitive definition of environmental performance can be proposed as respect for the environmental field in the context of economic activities. However, "respect" has a rather broad and indecisive meaning. It may mean respect for environmental regulations, respect for societal expectations related to the environment, respect for the firm's environmental objectives, or respect for the ecosystem's initial state where economic and industrial activities occur. These understandings of environmental performance revolve around more explicit axes concerning success, result, and action. The most frequently cited attributes focus on impact reduction, measurements (life cycle analysis, material-flow analysis, etc.), compliance, and stakeholder relations. This last dimension is synonymous with legitimacy.

\subsubsection{Environmental performance as a managerial issue}

Various economic institutions define environmental performance as the results of management systems in relation to the firm's control over its environmental aspects, aims, and targets (Albertini, 2016). The standard ISO 14001 considers environmental performance as the environmental management system's quantifiable results. This norm is oriented towards processes (Johnstone, 2020). It details how to implement a management system while considering environmental performance as measurements.

These environmental measurements include the development, use, and interpretation of relevant indicators to judge the value of what is measured. The question of indicators' selection may then arise. What indicators for what performance?

Bajec et al. (2020) note that conventional sustainable indicators are not enough as they often focus only on the economic perspective. But, while demand is growing for relevant information to assist the decision making (Ilinitch et al., 1998), we notice the literature offers several performance indicators (Saidani et al., 2019) having different purposes, scopes, and possible usages. However, this diversity of indicators makes the decisions even more difficult. It is up to the players to consider their choices, each from their point of view. Hence, the problem of the common understanding of performance emerges again.

\subsubsection{Environmental performance as impact reduction}

In the managerial literature, environmental performance, or corporate environmental performance (CEP), often represents an organization's commitment to reducing and preventing its impact on the environment (Johnstone, 2020). Impacts or externalities are often considered as market failures (Berta, 2019). This aspect refers to bad externalities when the effect of production or consumption of goods and services causes others' costs.

In order to reduce impacts, innovation seems a right solution (Madaleno et al., 2020). Firms achieve better performance when they decide to facilitate innovation and take it as strategies for their development (Bach et al., 2019). Performance would be like the result of continuous progress. This progress is often driven by innovation. It can be motivated by competitiveness or by new issues as environmental or societal ones. According to Schumpeter (Nicholas, 2003), innovation, in its globality, and new technologies "strikes not only at the margins of the profits and outputs of existing firms but at their foundation and very lives".

\subsubsection{From conformity to legitimacy}

Public policies are essential to resolve environmental issues (Scruggs, 2003). Porter and Van der Linde (Sánchez-Medina et al., 2013) argue that environmental compliance improves either environmental performance or economic performance resulting in a win-win situation through environmental innovation. In other words, regulatory constraints, if well-designed, are incentives for innovation and environmental disclosure (Sohn \& Lee, 2020). 
Compliance is linked to the organizational management agenda and encourages environmental decisions (Kraus et al., 2020). Furthermore, regulatory stringency mainly impacts economic costs to improve both financial and environmental performance. In this context, DiMaggio and Powell (1991) explained the homogeneity of practices by the influence of their institutional environment in search of a notion essential to their survival: legitimacy. They identified three mechanisms (or isomorphisms) to describe the institutional pressure (Baddache et al., 2013):

- Coercive isomorphism: Related to constraints imposed by public organizations or private ones in a strong position

- Normative isomorphism: Concerns professional environments that apply standards aligning with cultural norms

- Mimetic isomorphism: Applied in a situation of high uncertainty when organizations start to emulate other ones seen as role models.

Whereas compliance refers to the conformity with standards (technical conformity) or respect for laws (regulatory conformity), legitimacy is more complex to characterize. It concerns the recognition from the stakeholders, including suppliers, customers, and even society.

This theory can explain some aspects of the organization's activities concerning environmental and societal issues while seeking legitimacy regarding society and its stakeholders. As environmental problems become increasingly severe, more stakeholders are concerned about the influence of their industrial activities on the environment and their responsibility to fulfil environmental objectives (Wang et al., 2020). Also, clients' expectations are a top motivator for green practices adoption according to legitimacy if their demand is satisfied. Legitimacy is a recognition seen as value creation for an organization, whereas compliance is more identified as an objective to satisfy.

\subsubsection{Synthesis}

Environmental performance is, like performance, action, results, and success. But, it is linked to concrete dimensions that are: environmental management, sustainable expectations (related to economic and social concerns), environmental impacts, regulatory compliance, and legitimacy. As noticed in section 2, time influences objectives, processes, and measurements. The innovation dimension can be related to all fields (performance itself is continuous progress) but has a strong link with regulatory compliance that boosts it, environmental impacts, and more generally with industrial processes.

These environmental dimensions are represented in Figure 2. It is inspired by the definition of performance depicted in Figure 1.

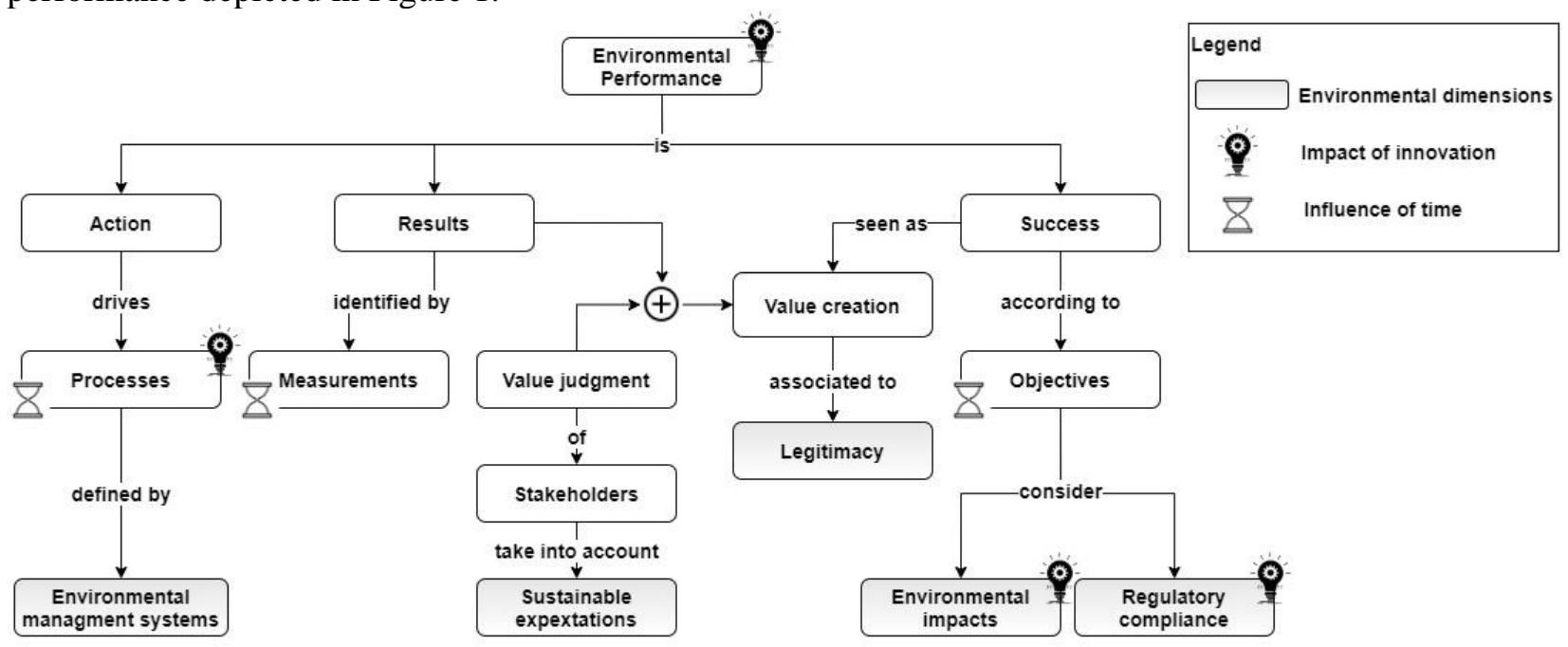

Figure 2. Characterization of environmental performance's dimensions according to the literature review (Source: Authors)

\section{ENVIRONMENTAL PERFORMANCE IN INDUSTRY}

The environmental dimensions, raised from the literature and presented in section 3 , are global to a company. However, in an industrial context, the apprehension of environmental performance in design 
projects is often different from the execution stage. That might lead to misunderstandings and generate unpredictable issues.

\subsection{Infrastructure projects}

Infrastructure projects are characterized by their societal interest (for example, linking cities with railroads) and their environmental impacts. They are usually not considered eco-friendly (Fuertes et al., 2013 and Cabello Eras et al., 2013). They generate a "fairly large" amount of pollutants compared to other projects (Falqi et al., 2020). Impacts as waste generation, air/water/soil pollution, gas emissions, noise and vibrations, biodiversity damage, and consumption of lands are always evocated. Yet, environmental questions, that vary at each phase of the project, are perceived as subjective issues related to the person who treats them while the choices taken at a certain phase involve direct consequences in the following stages (Nowak, 2017). Also, the diversity of stakeholders including clients who are top motivators of environmental policies (Onubi et al., 2020) makes consensus even more difficult.

\subsection{Application to railway infrastructure projects}

\subsubsection{Methodology}

Railway sector is composed of railroads, tunnels, bridges, substations, electric lines etc. (Fracchia et al., 2012). Our diagnosis analyses the industrial comprehension of environmental issues in this sector. The aim is to improve the understanding of environmental performance of design projects.

These projects concern the railway infrastructure manager, SNCF Réseau, responsible for developing and modernizing the French rail network.

The diagnosis is inspired by the Delphi method (Landeta, 2006), where experts are invited to give their individual opinion and talk together if no consensus. The purpose of such an approach is to obtain the most reliable agreement on an issue. The goal, here, is to identify the comprehension of the actors' environmental performance during the multiple phases of a project. Thus, it is possible to understand the potential existing gaps when comparing to the literature. In this case, various collaborators of railway infrastructure projects were asked to answer an online survey before a three hours' physical collective workshop. Three open questions have been addressed in the survey:

1. What synonym could you attribute to environmental performance?

2. Which are the three primary themes related to it for you?

3. Which are the three main indicators that measure it correctly?

The three questions are very similar. They ask intrinsically the same question: "How do you understand environmental performance?". While question 1 can reveal a first degree of comprehension, the two other questions are practically the same and point to a daily vision of environmental issues. 46 participants of $83(55 \%)$ answered the survey. They are experts in their domain, confronted with environmental issues but not necessarily issued from the environmental field, and participate in railway projects during different phases. 13 participants are concerned by the design phase (mostly engineers), and 33 participants are mainly affected to the execution of projects (operational staff). Subsequently, a workshop was held to discuss environmental issues and to present each other's actions. A debate took place on the vision of environmental performance and the undertaken actions. Key themes quickly reached a consensus for the vision of environmental performance, design implication, and future monitoring.

\subsubsection{Results}

Answering the first question, the participants reveal globally the consideration of 14 major categories depending on the phase from each actor mainly comes. The results are presented in Table 1.

The understanding of environmental performance is mainly associated to the reduction of environmental impacts (about 30\% for each phase). It is a well-known characteristic for infrastructure projects. $15.4 \%$ of design phase's participants linked environmental performance to the reduction of environmental costs, while $18.2 \%$ of execution phase's participants understood it as the definition and accomplishment of environmental objectives (in other words, efficiency and effectiveness). However, $15 \%$ of design participants and 9\% of execution's actors were not been able to define environmental performance. One answer called the two words performance and environment contradictory.

Another definition was 'sustainable development' (15.4\% in design phase and $9.1 \%$ in execution phase), a general concept with sometimes no more explanation. 
Table 1. Classification of collaborators returns for question 1 (by alphabetical order)

\begin{tabular}{|c|c|c|}
\hline Definition of env. performance & $\begin{array}{c}\text { Percentage of answers from actors in } \\
\text { design phase (\%) }\end{array}$ & $\begin{array}{c}\text { Percentage of answers from actors in } \\
\text { execution phase (\%) }\end{array}$ \\
\hline Definition of env. objectives & & 18,2 \\
\hline Env. disclosure & & 3,0 \\
\hline Env. integration in activities & & 6,1 \\
\hline Env. progress & & 3,0 \\
\hline Env. respect & & 3,0 \\
\hline Env. evaluation & & 6,1 \\
\hline Impact reduction & 30,8 & 27,3 \\
\hline Involvement & & 3,0 \\
\hline Managerial issue & 7,7 & \\
\hline Quality & 7,7 & \\
\hline Reduce env. costs & 15,4 & \\
\hline Regulatory compliance & 7,7 & 3,0 \\
\hline Risk managment & & 9,1 \\
\hline Sustainable development & 15,4 & 9,1 \\
\hline No Response & 15,4 & 9,1 \\
\hline
\end{tabular}

More developed ideas appear in the next two questions. The replies to question 3 were used as indicators of coherence with the themes of question 2. For example, the participants considered waste recycling as an indicator of waste management. Others considered energy consumption as a dimension and as an indicator of itself. The answers were then regrouped into three topics as asked in the survey for each participant issued from the responses to questions 2 and 3. Figure 3 presents 15 cited subjects and each answer's percentage according to the actor's phase (design or execution).

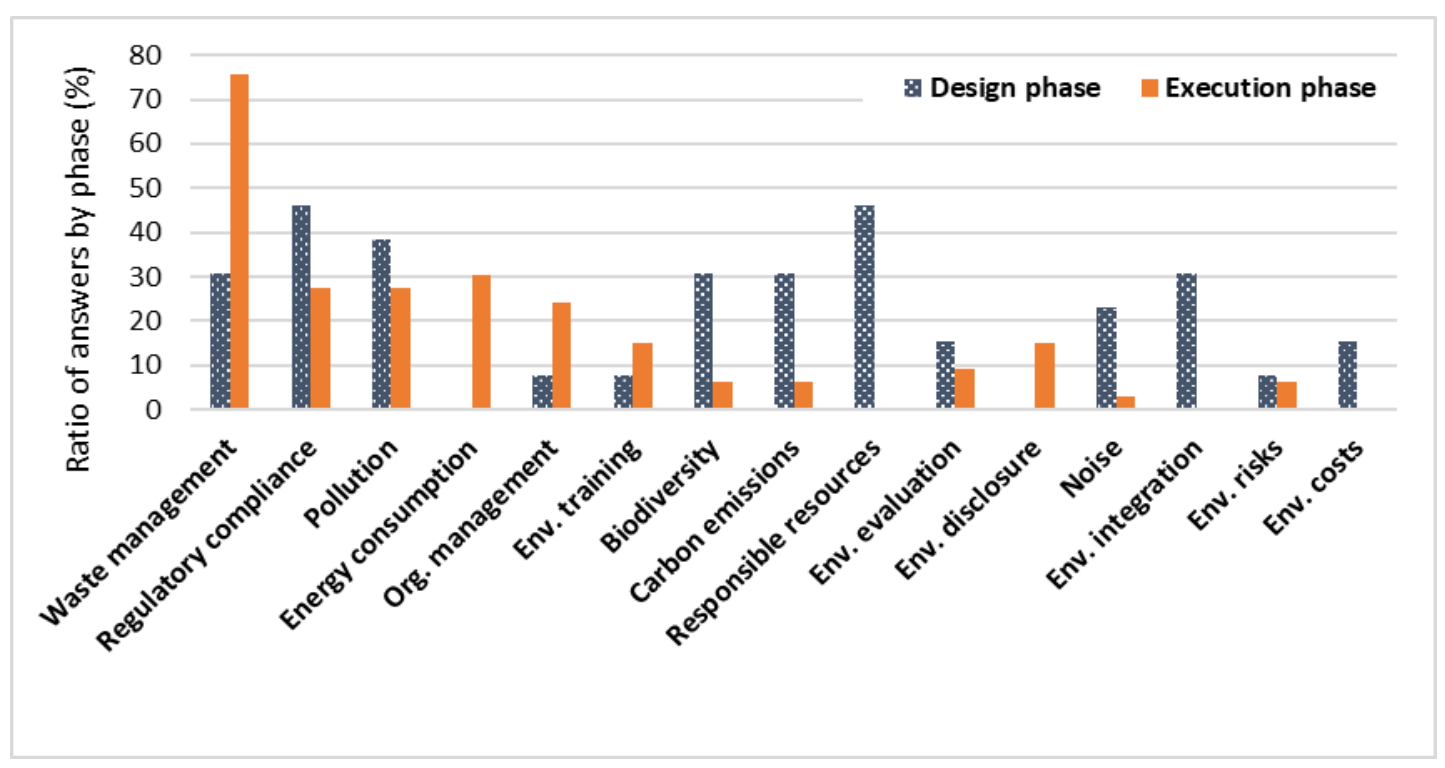

Figure 3. Environmental dimensions by phase according to the industrial diagnosis (order: from the most to the lest cited thematic)

Waste management is crucial for the actors, especially in the execution phase. Also, some revealed themes are the same but taken from different points of view. For example, while in design, the used words for indicating carbon footprint are carbon emissions, the execution actors use energy consumption. Even though the thematic is the same, different terms are used. This case underlines the importance of disclosure between actors. It is noticed that an eco-design for infrastructure project focuses on responsible resources, carbon footprint, pollution, environmental integration of activities through the definition of measurable objectives, regulatory compliance of decisions, and environmental costs.

\subsubsection{Consensus after the workshop}

After proposing many individual visions of environmental performance, the actors discussed their environmental issues, presenting their experience and their understanding of a responsible design 
project. A consensus was made to define environmental performance as the achievement of measurable environmental objectives limiting the industrial activities' impacts.

As presented in our literature review, achievement of targets is related two main notions: effectiveness and efficiency. These to notions were not directly mentioned in the definition. But, they are implicitly and directly related to the fulfilment of environmental objectives. These last are mainly defined in the design phase and related to the reduction of environmental impacts of all the project's phase. That is why, disclosure to stakeholders is essential from the early steps of an infrastructure project in order to anticipate environmental issues in the later phases.

\section{DIscussion}

The literature review characterized environmental performance considering three main axes: actions (processes and management systems), results (measurements, environmental evaluation as found in the diagnosis) and success (fulfilment of objectives and value creation).

The industrial diagnosis identified the main dimensions of environmental performance regarding the project's internal actors. Environmental performance is multidimensional but also depends on the time scale and the project's stage. Certain environmental themes are more prominent in one phase than in another (design or execution), as the case of waste management in execution. Also, environmental performance is not expressed in the same words. Everyone can see it according to their position and the problems they face. It is noted, for example, that the execution phase's participants did not mention the economic link attached to environmental performance, whereas it was mentioned in the design phase.

Execution actors often cited the theme of management systems. These systems are linked to environmental communication, information sharing, and mutual exchange between the projects' different actors. It is also a question of defining measurable criteria as a comparison baseline.

The consensus reached insisted on the fulfilment of environmental objectives. It is then a question of effectiveness, to fulfil all the objectives, and efficiency, to fulfil in the best way. Therefore, it is mandatory to connect all the actions at different scales and to move from a private initiative to productive governance.

Comparing our results, major environmental dimensions are cited both in literature and in the diagnosis. Related work focuses the consensus on objectives (part of the success dimension) and environmental impacts. However, success is mainly related to value creation and legitimacy. It is the central key of the neo-institutional theory (DiMaggio and Powell,1991). Neither value creation nor legitimacy were mentioned in the industrial answers. This case is representative of the industrial culture: environmental performance can be formulated, at least, as a constraint, or considered no more than individual initiatives.

Thus, the definition of environmental performance, and then environmental objectives, must be implemented from the design phase, where decisions continue to impact the entire project over time. Justifying the interest of environmental performance needs to adopt a value-creation perspective related to legitimacy. This legitimacy can be moral with regards clients and society, albeit more financial with regards to economic organizations, whose primary purpose is profit generation). Linking environmental and economic performances could thus be a benefit for the consideration of environmental concerns. For example, monetarizing environmental impacts, and actions limiting them, can explain the choice of various environmental decisions. In this context, a whole literature defines criteria and methodologies to monetarize externalities (Bithas, 2011).

Thus, a sustainable design should address all the environmental dimensions concerning stakeholders in order to justify choices undertaken in the latter stages. This can be done by implementing managerial modes of governance allowing disclosures between stakeholders who do not communicate sufficiently (Baddache et al., 2013). These modes should justify their undertaken decisions from an ethical, moral, and economic point of view by considering the legitimacy and profitability of environmental choices.

\section{CONCLUSION}

Performance has long been taken into account from an economic point of view. It has been, and sometimes remains, associated with profitability. However, a consideration of the natural environment in industrial projects becomes necessary for all stakeholders.

This article studied environmental performance from a literature review and an industrial diagnosis based on rail infrastructure design projects' stakeholders. 
As presented in this paper and according to the associated literature review, environmental performance is complex and multidimensional. As our industrial diagnosis has shown, each actor perceives it according to his experience and understanding of the subject. A clear, new, and 'field' definition has been proposed. It is based on three main axes: action, results, and success. Its purpose is to help industrialists and their understanding of environmental performance despite a potential lack of exhaustive knowledge in the field.

Answering our research question, we propose to:

- Initiate a continuous 'environmental' dialogue between the different stakeholders of the various project phases within a defined means of governance to disclose information and arrive on a consensus on definitions, measurements, and indicators

- Consider all the environmental themes that can emerge in a project from the upstream phase, the design stage where choices impact the following stages.

- Approach environmental performance as an added-value, so as a real performance, rather than a regulatory issue. We propose integrating all environmental externalities in the projects' socioeconomic evaluation. Such an approach can justify environmental decisions (legitimacy) and boost environmental innovation.

Our paper has certainly some limitations (no comparison with other railway companies, needs exploring other fields or considering more stakeholders). However, it reflects the reality on the ground concerning the understanding of environmental issues. This article introduces a future work on managing environmental performance for rail projects based on technical and economic indicators.

\section{ACKNOWLEDGMENTS}

We thank SNCF Réseau, Benoit ALIADIERE and Delphine BOUTAUD for their contribution to this research paper and for their motivation. We acknowledge the support and involvement of Patrizia GREGORI during the industrial diagnosis. We also thank Laboratoire Genie Industriel of CentraleSupélec and Université Paris-Saclay for their encouragements.

\section{REFERENCES}

Albertini, E. (2016), "Environmental Performance”, in Carroll, C. (Ed.), The SAGE Encyclopaedia of Corporate Reputation, SAGE Publications, Inc., pp. 275-281. https://doi.org/10.4135/9781483376493

Bach, T. M., Dalazen, L. L., da Silva, W. V., Ferraresi, A. A., and da Veiga, C. P. (2019), "Relationship Between Innovation and Performance in Private Companies: Systematic Literature Review", SAGE Open, Vol. 9, No. 2, pp. 1-17. https://doi.org/10.1177/2158244019855847

Baddache, F. and Nicolai, I. (2013), "Follow the leader: how corporate social responsibility influences strategy and practice in the business community", Journal of Business Strategy, Vol. 34 No. 6, pp. 26-35. https://doi.org/10.1108/JBS-01-2013-0002

Bajec, P., Tuljak-Suban, D., and Bajor, I. (2020), “A warehouse social and environmental performance metrics framework”. Promet - Traffic \& Transportation, Vol. 32, No. 4, pp. 513-526. https://doi.org/10.7307/ptt.v32i4.3390

Berta, N. (2017), "On the definition of externality as a missing market", European Journal of the History of Economic Thought, Vol. 24, No. 2, pp.287-318. https://doi.org/10.1080/09672567.2016.1169304

Bithas, K. (2011), "Sustainability and externalities: Is the internalization of externalities a sufficient condition for sustainability?”, Ecological Economics, Vol. 70, No. 10, pp. 1703-1706. https://doi.org/10.1016/j.ecolecon.2011.05.014

Bourguignon, A. (1997). "Sous les pavés la plage? ou les multiples fonctions du vocabulaire comptable : l'exemple de la performance.” Comptabilité - Contrôle - Audit, Vol. 3, No. 1, p. 89- 101. https://doi.org/10.3917/cca.031.0089

Cabello Eras, J. J., Gutiérrez, A. S., Capote, D. H., Hens, L., and Vandecasteele, C. (2013), "Improving the environmental performance of an earthwork project using cleaner production strategies", Journal of Cleaner Production, Vol. 47, pp. 368-376. https://doi.org/10.1016/j.jclepro.2012.11.026

DiMaggio, P. J. and Powell, W. (1991), "The iron cage revisited: Institutional isomorphism and collective rationality in organizational fields", in W. W. Powell and P. J. DiMaggio (Eds.), The new institutionalism in organizational analysis, pp. 63-82, Chicago: University of Chicago Press.

Dou, G., and Cao, K. (2020), "A joint analysis of environmental and economic performances of closed-loop supply chains under carbon tax regulation", Computers and Industrial Engineering, Vol.146. https://doi.org/10.1016/j.cie.2020.106624 
Falqi, I., Alsulamy, S., and Mansour, M. (2020), "Environmental Performance Evaluation and Analysis Using ISO 14031 Guidelines in Construction Sector Industries”. Sustainability, Vol. 12, No. 5. https://doi.org/10.3390/su12051774

Fracchia , M., Carlson R., Steckler P., Oberhauser A., Leitao N. (2012), "Enhance the Environmental Performance of Railway Infrastructure", Procedia - Social and Behavioral Sciences Vol. 48, pp. 1047 - 1057. https://doi.org/10.1016/j.sbspro.2012.06.1081

Fuertes, A., Casals, M., Gangolells, M., Forcada, N., Macarulla, M., and Roca, X. (2013), “An Environmental Impact Causal Model for improving the environmental performance of construction processes", Journal of Cleaner Production, Vol. 52, pp. 425-437. https://doi.org/10.1016/j.jclepro.2013.02.005

Garza-Reyes, J.A. (2015), "Lean and green - a systematic review of the state of the art literature", Journal of Cleaner Production, Vol. 102, pp. 18-29. https://doi.org: 10.1016/j.jclepro.2015.04.064

Ghalem, Â., Okar, C., Chroqui, R., and Semma, E. (2016), "Performance: A concept to define", Logistica, EST Berrechid - Morocco, May 2016, pp. 1-12. https://doi.org/10.13140/RG.2.2.24800.28165

Ilinitch, A. Y., Soderstrom, N. S., and E. Thomas, T. (1998), "Measuring corporate environmental performance", Journal of Accounting and Public Policy, Vol. 17, No. 4-5, pp. 383-408. https://doi.org/10.1016/S02784254(98)10012-1

Johnstone, L. (2020), “The construction of environmental performance in ISO 14001-certified SMEs", Journal of Cleaner Production, Vol. 263. https://doi.org/10.1016/j.jclepro.2020.121559

Kraus, S., Rehman, S. U., and García, F. J. S. (2020), “Corporate social responsibility and environmental performance: The mediating role of environmental strategy and green innovation", Technological forecasting and social change, Vol. 160. https://doi.org/10.1016/j.techfore.2020.120262

Landeta, J. (2006), "Current validity of the Delphi method in social sciences", Technological forecasting and social change, Vol. 73, pp. 467-482. https://doi.org/10.1016/j.scitotenv.2020.136855

Lebas, M. J. (1995), "Performance measurement and performance management", International Journal of Production Economics, Vol. 41, No. 1-3, pp. 23-35. https://doi.org/10.1016/0925-5273(95)00081-X

Madaleno, M., Robaina, M., Dias, M. F., and Meireles, M. (2020), "Dimension effects in the relationship between eco-innovation and firm performance: A European comparison”, Energy Reports, Vol. 6, pp. 631637. https://doi.org/10.1016/j.egyr.2019.09.038

Moullin, M. (2007), "Performance measurement definitions: Linking performance measurement and organisational excellence”, International Journal of Health Care Quality Assurance, Vol. 20, No. 3, pp. 181-183. https://doi.org/10.1108/09526860710743327

Nicholas, T. (2003), "Why Schumpeter Was Right: Innovation, Market Power and Creative Destruction in 1920s America”, Journal of Economic History, Vol.63, No. 4, pp. 1023 - 1058

Nowak, M. (2017), "Defining Project Approach using Decision Tree and Quasi-hierarchical Multiple Criteria Method”, Procedia Engineering, Vol. 172, pp. 791-799. https://doi.org/10.1016/j.proeng.2017.02.125

Onubi, H. O., Yusof, N. A., and Hassan, A. S. (2020), "How environmental performance influence client satisfaction on projects that adopt green construction practices: The role of economic performance and client types", Journal of Cleaner Production, Vol. 272. https://doi.org/10.1016/j.jclepro.2020.122763

Pesqueux, Y. (2005), "La notion de performance globale", $5^{\circ}$ Forum international ETHICS, Tunis, Dec 2004, halshs-00004006

Saidani, M., Yannou, B., Leroy, Y., Cluzel, F., and Kendall, A. (2019), “A taxonomy of circular economy indicators”, Journal of Cleaner Production., Vol. 207, pp. 542-559. https://doi.org/10.1016/ j.jclepro.2018.10.014

Sánchez-Medina, P. S., Díaz-Pichardo, R., Bautista-Cruz, A., and Toledo-López, A. (2013), "Environmental Compliance and Economic and Environmental Performance: Evidence from Handicrafts Small Businesses in Mexico", Journal of Business Ethics, Vol. 126, No.3, pp. 381-393. https://doi.org/10.1007/s10551-0131945-2

Scruggs, L. (2003), "Environmental performance in industrial democracies", Cambridge university press. UK

Siegel, J. P., and Summermatter, L. (2008), "Defining Performance in Public Management: A Survey of Academic Journals", Public Administration, pp. 1-34

Wang, S., Wang, H., Wang, J., and Yang, F. (2020), "Does environmental information disclosure contribute to improve firm financial performance? An examination of the underlying mechanism", Science of the Total Environment, Vol. 714, No.96. https://doi.org/10.1016/j.scitotenv.2020.136855

World Commission on Environment and Development (1987), Our Common Future, Oxford and New York: Oxford University Press 